\title{
Report from the Executive Committee Meeting in Tbilisi, 4-6 November 2016
}

Richard Elwes, EMS Publicity Officer and Sjoerd Verduyn Lunel, EMS Secretary

The Executive Committee of the EMS met in Tbilisi, 4-6 November 2016, at Ivane Javakhishvili Tbilisi State University, on the kind invitation of the Georgian Mathematical Society. As well as the committee's current incumbents, several incoming members for 2017 also attended by invitation, making this event something of a handover. On Friday evening, the gathered assembly enjoyed a warm welcome from Roland Duduchava, Otar Chkadua and Tinatin Davitashvili (President and Vice-Presidents of the Georgian Mathematical Society), as well as Mikhail Chkhenkeli, Vice-Rector of Tbilisi State University. The oldest university in the Caucasus, it was founded in 1918 by the historian Ivane Javakhishvili, with, amongst others, the mathematician Andrea Razmadze, after whom the mathematics institute is named.

\section{Officers' Reports and Membership}

President Pavel Exner welcomed all members and guests and opened the meeting by relating his recent activities. The treasurer, Mats Gyllenberg, then presented his report on the society's 2016 income and expenditure, recording healthy results. Thus, the EMS can afford to maintain its recently elevated expenditure on scientific projects. He then presented the society's budget for 2017.

The committee was pleased to approve a list of 54 new individual members. The office has received no new applications for corporate membership, although there have been enquiries that may develop. Too many individual members remain in arrears, although several have belatedly paid their dues after a reminder. The office will continue to chase outstanding payments. The conversation then turned to the thornier problem of member societies that are perpetually in arrears. The society is mindful of the financial difficulties that national mathematical societies can experience. Nevertheless, the committee previously agreed the principle that membership will lapse for societies that neither pay their dues nor respond to letters from the president. In early 2016, the president wrote to all corporate members badly in arrears. The committee thus resolved that he will now write final reminders to such members, warning them of the committee's intention to propose the termination of their membership at the next council meeting.

\section{ECMs $7 \& 8$}

This was the first meeting of the Executive Committee since the 7th European Congress of Mathematics (ECM) in Berlin in July. The committee considered a report from local organiser Volker Mehrmann. It was agreed that, on most metrics, the meeting was a great success and the committee reiterated its profound thanks to all involved. However, there were also problems, notably a surprising disparity between the number of people registering and those paying the registration fee. Consequently, the meeting ended up in financial deficit. The organisers of ECM8 must be aware of this danger.

The committee opted to amend the profile for members of future ECM Scientific Committees, who should not only be top mathematicians but also people with broad mathematical interests willing to attend the event in person.

This was also the first Executive Committee meeting since the venue of the 8th European Congress was settled at July's council meeting: it will be held in Portorož in Slovenia, 5-11 July 2020. Local organiser Tomaz Pisanski delivered a presentation on preparations so far, including some thoughts on the philosophy of the congress. In the ensuing discussion, the committee contemplated the mission of the ECM in our changing mathematical world. How can we use such events to strengthen our community? How can we help young mathematicians feel welcome? Some initial ideas were aired and it was agreed that this was an important topic that will be revisited.

\section{Other Scientific Meetings}

The committee discussed reports from the 2016 EMS Summer Schools and agreed that these were scientifically successful and a worthwhile use of EMS resources. Considering recommendations from the Meetings Committee, support for four 2017 Summer Schools was approved. It was decided to require applicants for Summer School funding to provide more details on topics such as geographic, age and gender distributions of participants. The remit for the Meetings Committee was then adapted to encourage a more proactive approach to attracting proposals and thus hopefully increasing competition. It may also be useful to publicise recent successful Summer Schools.

Committee member Alice Fialowski reported from the EMS Distinguished Speaker talk, delivered by Ernest Vinberg at the 50th Seminar Sophus Lie. It was agreed to increase the level of ceremony at EMS Distinguished Speaker events to reflect the honour of the award. EMS Distinguished Speakers for 2017 were decided: Mireille 
Bousquet-Mélou at the Conference on Foundations of Computational Mathematics (Barcelona, 10-19 July 2017) and Kathryn Hess at the Meeting of the Catalan, Spanish and Swedish Math Societies (Umeå, 12-15 June, 2017).

The committee agreed that the EMS will endorse the following events: the 9th European Student Conference in Mathematics, EUROMATH-2017 (Bucharest, 29 March-2 April 2017); the 2nd Academic University Student Conference 2017 (15-19 November 2017, Larnaca, Cyprus); and the 11th European Conference on Mathematical and Theoretical Biology (Lisbon, 23-27 July 2018).

Meanwhile, the EMS-Bernoulli Society Joint Lecture for 2017 will be given by Alexander Holevo at the 31st European Meeting of Statisticians (Helsinki, 24-28 July 2017).

The committee approved separate funding for the Applied Mathematics Committee for scientific activities, to the tune of 5,000 euros in 2017 and 10,000 euros in 2018 (bearing in mind that 2018 is the Year of Mathematical Biology).

\section{Society Meetings}

The Executive Committee discussed the president's report from the council meeting from July and contemplated ways to make it a more interactive event. This conversation will be continued at future meetings. The committee was delighted to accept an invitation from the Czech Mathematical Society to hold the 2018 Council in Prague.

The next Executive Committee meeting will be held on 17-19 March in Bratislava and the next meeting of the Presidents of Member Societies will be held on 1-2 April 2017 in Lisbon.

\section{Standing Committees \& Projects}

With numerous upcoming vacancies across the society's 11 standing committees (excluding the Executive Committee), the committee expressed its sincere appreciation to all outgoing members for their efforts in carrying out the society's work. It was then pleased to fill these places, including appointing Jürg Kramer as Chair and Tine Kjedsen as Vice-Chair of the Education Committee, Sandra di Rocco as Chair and Stanislaw Janeczko as ViceChair of the European Solidarity Committee, Michael Drmota as Chair and Ciro Ciliberto as Vice-Chair of the Meetings Committee, and Alessandra Celletti as Chair of the Women in Mathematics Committee.

The society's standing committees will soon reduce to 10 , following a decision to merge the Publishing and Electronic Publishing Committees. The details, and further appointments to the combined committee, will await the outcome of a discussion between the two. The Executive Committee then approved an updated remit for the Ethics Committee.

The Chair of the Committee for Developing Countries (CDC) Giulia Di Nunno, in attendance by invitation, then delivered a presentation on the CDC's work, including on the Emerging Regional Centres of Excel- lence programme and plans for the grant scheme for researchers from Africa (made possible by generous funding from the Simons Foundation for Africa). The Executive Committee thanked her for the CDC's excellent work and discussed ways to increase its visibility. EMS members should be reminded of the option of donating to the CDC when paying their EMS membership fees (the amount raised by this route has decreased in recent years).

Reports from the chairs of other standing committees were also discussed, along with reports from the Publicity Officer and Editor-in-Chief of the Newsletter, and reports on other EMS-affiliated projects including the European Digital Mathematical Library, Zentralblatt MATH and EU-MATHS-IN (the European Service Network of Mathematics for Industry and Innovation). The latter has had a proposal ("Mathematical Modelling, Simulation and Optimization for Societal Challenges with Scientific Computing") funded under the Horizon 2020 programme on user-driven e-infrastructure innovation. EU-MATHS-IN is also involved in making mathematics more visible in H2020 generally.

\section{Funding, Political and Scientific Organisations}

The president reported on recent developments in Horizon2020 and the European Research Council. He also discussed the new legal status of the Initiative for Science in Europe (ISE), reminding the committee that the fee for ISE membership for the EMS is set to double to 3,000 euros. Thus, after two years, the benefits of ISE membership will be re-evaluated. The president gave a short report about ESOF (EuroScience Open Forum) in Manchester in July 2016, noting that the Committee for Raising Public Awareness had run a successful panel session on "The Myth of Turing".

There are live bids from both Paris and St. Petersberg for the ICM in 2022. The EMS is supporting both. The committee also discussed EMS ongoing business with other mathematical organisations, including ICIAM, the Abel Prize, CIMPA, the Fermat Prize and various research facilities around Europe.

\section{Conclusion}

The meeting was closed with enthusiastic thanks to our hosts, the Georgian Mathematical Society (particularly its President Roland Duduchava) and Tbilisi State University for excellent organisation and generous hospitality. 